\title{
$\mathrm{SmFeN}$ 系磁石の開発と展望
}

$\begin{array}{llll}\text { 久米道也 } & \text { 冨本高弘 } & \text { 山本宗生 } & \text { 井原公平 } \\ \text { 吉原秀明 } & \text { 多田秀一 } & \text { 住友三幸 } & \end{array}$

日亜化学工業株式会社

J. Japan Inst. Metals, Vol. 76, No. 1 (2012), pp. 107-111

Special Issue on Recent Progresses of Materials Science of Rare Earth Permanent Magnet Materials and Their Perspectives (C) 2012 The Japan Institute of Metals OVERVIEW

\section{Progress and Prospects of SmFeN Magnets}

Michiya Kume, Takahiro Tomimoto, Muneo Yamamoto, Kohei Ihara, Hideaki Yoshiwara, Shuichi Tada and Miyuki Sumitomo

Nichia Corporation, Anan 774-8601

More than 20 years have passed since $\mathrm{SmFeN}$ was discovered. At that time, because of its huge anisotropy field and high Curie temperature, $\mathrm{SmFeN}$ was expected to become a next-generation permanent magnetic material. However, $\mathrm{SmFeN}$ has the drawback that it cannot be sintered. Although considerable research has been carried out, this problem has still not been overcome. Therefore, SmFeN magnets have less potential for mass commercialization than NdFeB magnets. We propose two methods that are expected to lead to the commercial use of $\mathrm{SmFeN}$. One is to increase coercivity by controlling the shape of particles, consequently increasing heat resistance. The other is to form products with new magnetic patterns by examining the magnetic orientation process. Moreover, it is important to use all rare-earth elements efficiently. Thus, we consider that $\mathrm{SmFeN}$ should be reappraised as a magnetic material.

(Received July 1, 2011; Accepted October 27, 2011; Published January 1, 2012)

Keywords: samarium, iron, nitrogen, coercivity, magnet, anisotropy

\section{1. 緒言}

1990 年の Coey らの報告 ${ }^{1)}$ は衝撃的だった. 金属間化合物 に窒素を侵入させるだけで，飽和磁化は $50 \%$, キュリ一点 は $350^{\circ} \mathrm{C}$ 以上も上昇したからである.この発表から 20 年余 りが経過した現在, この材料の研究の歴史と今後の展望につ いて述べることを本稿の目的とする。

Coey らのアプローチは, 水素吸蔵の研究 ${ }^{2}$ に端を発する と思われる，一方，同時期に研究を行っていた Iriyama らの 出発点は, Kim らによる鉄-窒素薄膜の研究3)であるとされ ている4). 出発点が全く違う彼らが同じ結論に達したことが 興味深い。

さて Iriyama らの初期の報告5)において $\mathrm{Sm}_{2} \mathrm{Fe}_{17} \mathrm{~N}_{3}$ 組成の 異方性磁界 $H_{\mathrm{a}}$ は $20.7 \mathrm{MA} / \mathrm{m}$, 飽和磁化 $B_{\mathrm{s}}$ は $1.57 \mathrm{~T}$ とさ れた.この結果, $\mathrm{SmFeN}$ は $\mathrm{NdFeB}$ に匹敵するポテンシャ ルを持つと認知された. また Imaoka らによって, 金属に窒 素を導入するという独特のプロセスについての理解が進ん だ6).

一方で Coey らは $\mathrm{SmFeN}$ が $650^{\circ} \mathrm{C}$ で Fe と $\mathrm{SmN}$ に分解 することを報告した ${ }^{7)}$ 。このことが $\mathrm{SmFeN}$ の本格的な実用 化を阻む最大要因であり，言い換えれば焼結ができないとい う欠点を最初から抱えていたということになる。焼結ができ
ないゆえに様々なアプローチがなされたことも, $\mathrm{SmFeN}$ 研 究の大きな特徵である.

\section{2. ナノコンポジット化}

Schnitzke らは mechanical alloying 法で Sm リッチ側の $\mathrm{Sm}_{12.5} \mathrm{Fe}_{87.5}$ 組成合金を微細化したのちに窒化して, 固有保 磁力 $H_{\mathrm{cJ}}=2.4 \mathrm{MA} / \mathrm{m}$ を得た ${ }^{8)}$. Ding らは Fe リッチ側で同 様のプロセスを経て remanence enhancement 観測した. 最大エネルギー積 $(B H)_{\max }$ は真密度換算で $160 \mathrm{~kJ} / \mathrm{m}^{3}, H_{\mathrm{cJ}}$ は最大で $0.8 \mathrm{MA} / \mathrm{m}$ であった ${ }^{9)}$.

急冷薄帯プロセスでは, Katter らが $\mathrm{SmFe}$ 二元系におい て $\mathrm{Th}_{2} \mathrm{Zn}_{17}$ および $\mathrm{TbCu}_{7}$ 構造を得て, これらを窒化した。 $\mathrm{Th}_{2} \mathrm{Zn}_{17}$ 構造では残留磁化 $B_{\mathrm{r}}$ が $0.73 \mathrm{~T}, H_{\mathrm{cJ}}=1.67 \mathrm{MA} / \mathrm{m}$, $(B H)_{\max }=65.6 \mathrm{~kJ} / \mathrm{m}^{3}$, 一方 $\mathrm{TbCu}_{7}$ 構造では $B_{\mathrm{r}}=0.86 \mathrm{~T}$, $H_{\mathrm{cJ}}=0.49 \mathrm{MA} / \mathrm{m},(B H)_{\max }=69.6 \mathrm{~kJ} / \mathrm{m}^{3}$ の粉末を得た ${ }^{10)}$. Yamamoto らは 2-17 相の微細化を研究する過程において, バナジウムを添加することで $\mathrm{TbCu}_{7}$ 構造が生成する領域が あることを指摘した ${ }^{11)}$. Yoneyama らは Zr と Co 添加をす ることで $\mathrm{Fe}$ の多い領域で $\mathrm{TbCu}_{7}$ 構造を得て, これを窒化 することで $B_{\mathrm{r}}=0.94 \mathrm{~T}, H_{\mathrm{cJ}}=0.76 \mathrm{MA} / \mathrm{m},(B H)_{\max }=118$ $\mathrm{kJ} / \mathrm{m}^{3}$ を得た ${ }^{12)}$. その後, Kawashima らはボロンを加えて $B_{\mathrm{r}}=1.0 \mathrm{~T}, H_{\mathrm{cJ}}=0.76 \mathrm{MA} / \mathrm{m}, \quad(B H)_{\max }=156 \mathrm{~kJ} / \mathrm{m}^{3}$ を得 
た ${ }^{13)}$. 2011 年現在, $\mathrm{TbCu}_{7}$ 系の急冷薄帯は耐食性の良さを 生かし, 成形品として $(B H)_{\max }=110 \mathrm{~kJ} / \mathrm{m}^{3}$ 級の等方性圧縮 ボンド磁石として市販されている14).

\section{3. その他のプロセス}

薄膜化を始めとする高密度化へのアプローチがなされた. Rani らは $\mathrm{Sm}_{2} \mathrm{Fe}_{17} \mathrm{~N}_{x}$ 組成の薄膜を, スパッタとその後の窒 化で作成し，等方性ではあるが $H_{\mathrm{cJ}}=1.8 \mathrm{MA} / \mathrm{m}$ を得た ${ }^{15)}$. Jang らはスパッタで $\mathrm{ThMn}_{12}$ 構造の $\mathrm{SmFeN}$ 薄膜を得て, 結晶粒子径が $50 \mathrm{~nm}$ 以上の領域で $H_{\mathrm{cJ}}=0.32 \mathrm{MA} / \mathrm{m}$ 以上を 得た ${ }^{16)}$. Song らは $\mathrm{Sm}(\mathrm{Zr}) \mathrm{Fe}_{7} \mathrm{~N}_{x}$ 組成の薄膜を, スパッタ とそれに続く窒化で得て, 有意な $H_{\mathrm{cJ}}$ は得られなかったもの の，リコイル線から明瞭なスプリングバックが観測され た ${ }^{17)}$.

薄膜以外の研究は以下のと打りである。Otani らは $\mathrm{Sm}_{2} \mathrm{Fe}_{17} \mathrm{~N}_{x}$ 微粉末 $\left(H_{\mathrm{cJ}}=0.08 \mathrm{MA} / \mathrm{m}\right)$ を $15 \mathrm{vol} \%$ の $\mathrm{n}$ で固 めると $H_{\mathrm{cJ}}$ が $0.44 \mathrm{MA} / \mathrm{m}$ まで上昇することを報告した ${ }^{18)}$. Machida らは $\mathrm{Sm}_{2} \mathrm{Fe}_{17} \mathrm{~N}_{x}$ 粉末を $3 \mathrm{GPa}\left(550^{\circ} \mathrm{C}\right)$ の高圧力によ って結晶構造を保ちつつ真密度まで焼結したものの， $H_{\mathrm{cJ}}$ は 原料の三分の一程度まで低下した ${ }^{19)}$. Izumi らはジエチル $\mathrm{Zn}$ 溶液の光分解によって $\mathrm{Sm}_{2} \mathrm{Fe}_{17} \mathrm{~N}_{3}$ 粒子に薄い $\mathrm{Zn}$ 膜を コーティングしたのちにボンド磁石にすると, 保磁力の長期 安定性に優れるとし ${ }^{20)}$, さらに Fe の一部を Co 置換するこ とで成形品として $(B H)_{\text {max }}=186 \mathrm{~kJ} / \mathrm{m}^{3}$ を得た ${ }^{21)}$. Makita らは真空蒸着の要領で $\mathrm{Zn}$ 処理が可能なことを示し, 最大で $1.2 \mathrm{MA} / \mathrm{m}$ を超える $H_{\mathrm{cJ}}$ を得た ${ }^{22)}$. Sugimoto らは aerosol deposition 法で厚膜を作成し, 無配向で $B_{\mathrm{r}}=0.4 \mathrm{~T}, H_{\mathrm{cJ}}=$ $1.11 \mathrm{MA} / \mathrm{m}^{23)}$, 配向ありで $B_{\mathrm{r}}=0.54 \mathrm{~T}$ を得た ${ }^{24)}$. Saitoは spark plasma sintering 法で相対密度 $90 \%$ 以上の $\mathrm{Sm}_{2} \mathrm{Fe}_{17} \mathrm{~N}_{3}$ バルク体を作成し，Zn を 5 mass\%含んだ場合は $B_{\mathrm{r}}=0.52$ $\mathrm{T}, H_{\mathrm{cJ}}=0.75 \mathrm{MA} / \mathrm{m}$ を得た ${ }^{25)}$. Mashimo らは衝撃圧縮法で 空孔率が $5 \%$ 以下の $\mathrm{Sm}_{2} \mathrm{Fe}_{17} \mathrm{~N}_{3}$ バルク体を作成し， $B_{\mathrm{r}}=0.97$ $\mathrm{T}, H_{\mathrm{cJ}}=0.57 \mathrm{MA} / \mathrm{m},(B H)_{\max }=122 \mathrm{~kJ} / \mathrm{m}^{3}$ を得た ${ }^{26)}$.

\section{4. 粉 末 合 成}

Ishikawa らは微粒子合成技術として有していた還元拡散 法27)を使用し，金属の溶解工程を経ることなく $\mathrm{Sm}_{2} \mathrm{Fe}_{17}$ 合 金を得た.これを窒化後, 微粉砕した $\mathrm{Sm}_{2} \mathrm{Fe}_{17} \mathrm{~N}_{3}$ 粉末の磁 気特性は $B_{\mathrm{r}}=1.24 \mathrm{~T}, H_{\mathrm{cJ}}=1.07 \mathrm{MA} / \mathrm{m}$ であった ${ }^{28-30)}$. 2011 年現在, 成形品で $(B H)_{\text {max }}=110 \mathrm{~kJ} / \mathrm{m}^{3}$ 級の異方性射 出成形ボンド磁石として市販されている.

\section{5. 異 種 混 合}

O’Sullivan らは粒子径の違う $\mathrm{Sm}_{2} \mathrm{Co}_{17}$ と $\mathrm{Sm}_{2} \mathrm{Fe}_{17} \mathrm{~N}_{3}$ を混 合した成形体に抢いて， $H_{\mathrm{cJ}}$ と $B_{\mathrm{r}}$ の増強を確認した ${ }^{31)}$. Kitazawa らは $\mathrm{Sm}_{2} \mathrm{Fe}_{17} \mathrm{~N}_{3}$ 粉末と異方性 HDDR-NdFeB 粉末 を混合することで充填密度を向上し，前者が 30 mass\%のと きに, 成形品で $(B H)_{\max }=200 \mathrm{~kJ} / \mathrm{m}^{3}$ の圧縮成形ボンド磁石 を得た ${ }^{32)}$. Yamashita らは $\mathrm{Sm}_{2} \mathrm{Fe}_{17} \mathrm{~N}_{3}$ 粉末と異方性
HDDR-NdFeB 粉末を組み合わせ, さらにバインダーの化 学設計によって比較的低圧での圧縮成形を可能にして成形品 で $(B H)_{\max }=160 \mathrm{~kJ} / \mathrm{m}^{3}$ 級のボンド磁石を得た ${ }^{33)}$. また，こ れをモーターのロータに組み込んでモーター特性を評価し た ${ }^{34)}$. Fukunaga らは $\mathrm{NdFeB} / \mathrm{SmFeN}$ 磁石のフラックスロ スを, 単体磁石のそれから予測する手法について述べた ${ }^{35)}$.

\section{6. 改良された還元拡散法による粒子合成とその応用}

著者らの周辺には, 希土類を使用した蛍光体粉末の製造技 術や設備が整っていた. そこでこれらの技術を永久磁石材料 にも展開することが，研究のスタートであった。

\section{1 粉末合成}

著者らは $\mathrm{Sm}_{2} \mathrm{Fe}_{17} \mathrm{~N}_{3}$ が持つ良特性を磨くことに集中して いる. 良特性とは, 微粒子状態で磁気性能を発揮することで ある.このため, 還元拡散法をべースにして, 溶液からの素 原料調整, 予備還元や窒化処理の最適化等の研究を行ってき た．著者らは，これを改良された還元拡散法と呼び，これに よって従来にない形状の $\mathrm{Sm}_{2} \mathrm{Fe}_{17} \mathrm{~N}_{3}$ 粒子を得た. 粉末の $H_{\mathrm{cJ}}$ は量産べースで $1 \mathrm{MA} / \mathrm{m}, B_{\mathrm{r}}$ は $1.2 \mathrm{~T}$ から $1.3 \mathrm{~T}$ 程度であ る. Fig. 1 に示す $\mathrm{SEM}$ 写真は $\mathrm{Sm}_{2} \mathrm{Fe}_{17} \mathrm{~N}_{3}$ 粒子の代表的な 例である. 機械的な粉砕を伴わずに。平均粒子径約 $3 \mu \mathrm{m}$ の 球状の分散した粒子が得られている.

2011 年現在, この粉末は商業生産され, 主として射出成 形プラスチック磁石のコンパウンドとして市販されている. 高耐食性や一体成形が可能な点が評価されている.

\section{2 高保磁力化}

$\mathrm{Zn}$ 粉末を上記の $\mathrm{Sm}_{2} \mathrm{Fe}_{17} \mathrm{~N}_{3}$ 粉末に対して 5 mass\%混合し てアルゴンガス中 $427^{\circ} \mathrm{C}$ で熱処理すると, $\mathrm{Zn}$ 蒸気が粉末の 隙間を満たして Zn による表面処理が行われる.この結果, $H_{\mathrm{cJ}}$ は $1.04 \mathrm{MA} / \mathrm{m}$ から $1.6 \mathrm{MA} / \mathrm{m}$ まで上昇する, しかし $B_{\mathrm{r}}$ は 30\%低下する36).

一方, 還元拡散の前工程において適量のチタンを添加した 場合， $B_{\mathrm{r}}$ の低下を $9 \%$ 程度にとどめる一方で， $H_{\mathrm{cJ}}$ は 1.53 $\mathrm{MA} / \mathrm{m}$ まで上昇させることに成功した，これは還元拡散反

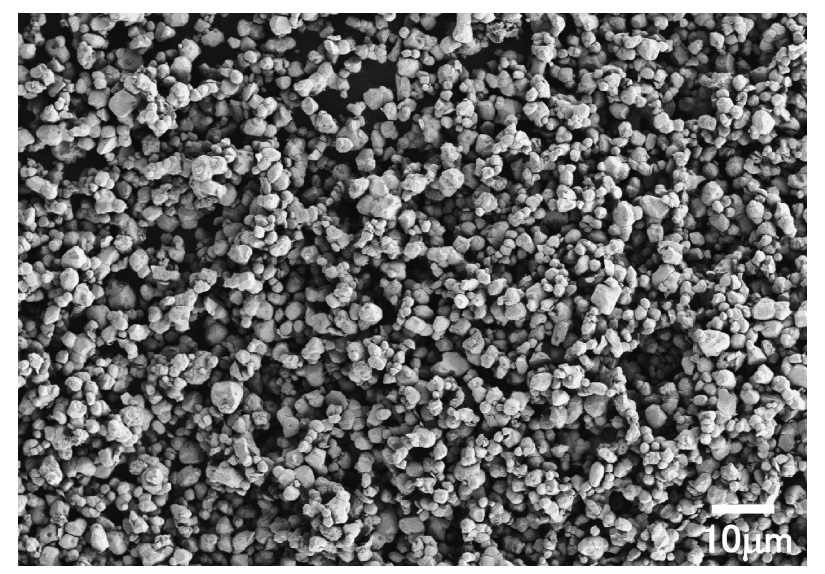

Fig. 1 SEM image of $\mathrm{Sm}_{2} \mathrm{Fe}_{17} \mathrm{~N}_{3}$ powder made by advanced reduction and diffusion method. 


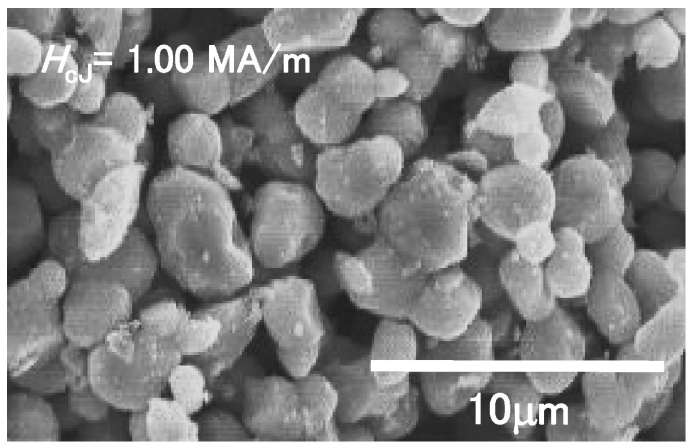

(a) Ti-less SmFeN

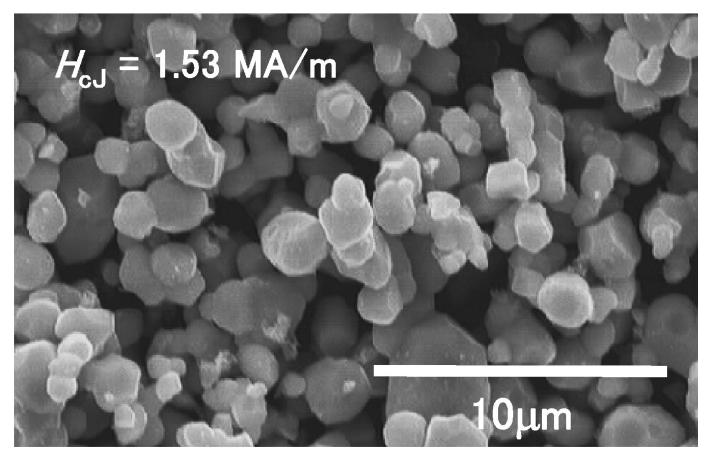

(b) Ti-added SmFeN

Fig. 2 SEM images of $\mathrm{Sm}_{2} \mathrm{Fe}_{17} \mathrm{~N}_{3}$ powder (a) Ti-less SmFeN, (b) Ti-added SmFeN.

応時の活性化エネルギーを低下させて，粒子の凝結を防ぎつ つも，一回り小さな粒子合成を狙ったものである.チタンな しの場合の $\mathrm{Sm}_{2} \mathrm{Fe}_{17} \mathrm{~N}_{3}$ 粉末の平均粒子径は $3 \mu \mathrm{m}$ であった が，チタンを添加した場合は $2.1 \mu \mathrm{m}$ であった ${ }^{37}$ (Fig. 2).

$\mathrm{Sm}_{2} \mathrm{Fe}_{17} \mathrm{~N}_{3}$ 粉末を熱可塑性樹脂と練り合わせる際には, どうしても酸化等による影響で $H_{\mathrm{cJ}}$ は低下する，このため， あらかじめ $H_{\mathrm{cJ}}$ を上げておくことで, PPS (poly phenylene sulfide)を始めとする高融点樹脂でのコンパウンドの実用化 を目指して研究を行っている.

\section{3 特殊成形品の例}

$\mathrm{Sm}_{2} \mathrm{Fe}_{17} \mathrm{~N}_{3}$ 射出成形磁石の特長は自由な形状が得られる ことである。また我々の作製した $\mathrm{Sm}_{2} \mathrm{Fe}_{17} \mathrm{~N}_{3}$ コンパウンド を使用して成形する場合, 射出成形金型に組み込まれた界磁 用永久磁石によって異方化が実施可能である. 著者らは, こ の特長を生かして様々な形状を持つ試作品を製作している.

例えば，Fig. 3 に示すような成形品では，ギャップ部分に 磁束が集中するように, 成形時に配向する向きを調整する. $\mathrm{Sm}_{2} \mathrm{Fe}_{17} \mathrm{~N}_{3}$ 射出成形磁石の $B_{\mathrm{r}}$ は高々 $0.75 \mathrm{~T}$ 程度であるが, 配向方向を工夫すれば焼結磁石に匹敵するだけの磁束密度を 得ることも可能である. Fig. 4 にはギャップ部の磁束密度を 示すとともに，配向方向の概略図を示す.

次の試作品はロッド磁石という細長い磁石である，ここで 紹介するロッド磁石の特徵は, 長手方向にリング状の $\mathrm{N}$ 極 $\mathrm{S}$ 極が周期的に現れることであり，コピー機などで使われる マグロールのように円周方向に沿って磁極が現れる点とは様 相が異なっている．長手方向に磁極を交互に発生させるため には, 一般的に, 小さな磁石を極が向かい合わせになるよう に非磁性の鞘の中に順次入れていく.しかし，この試作品で は成形一回で一体化した磁石が製作可能である.

Fig. 5 はロッド磁石の製作例である. 直径 $6 \mathrm{~mm}$, 長さ $275 \mathrm{~mm}$, 磁極数 20 極である. Fig. 6 に長手方向に計測し た表面磁束密度を示す. 最大で $0.4 \mathrm{~T}$ が得られるので, この 程度の小径磁石においては, 焼結ネオジ磁石を組久合わせて 使用するよりも, 本ロッド磁石の有用性が出てくると考えら れる.

最後に紹介する試作品が, 異形押出磁石である. 円筒形状 の磁石を, 連続的に異方化させながら押し出す技術を用い

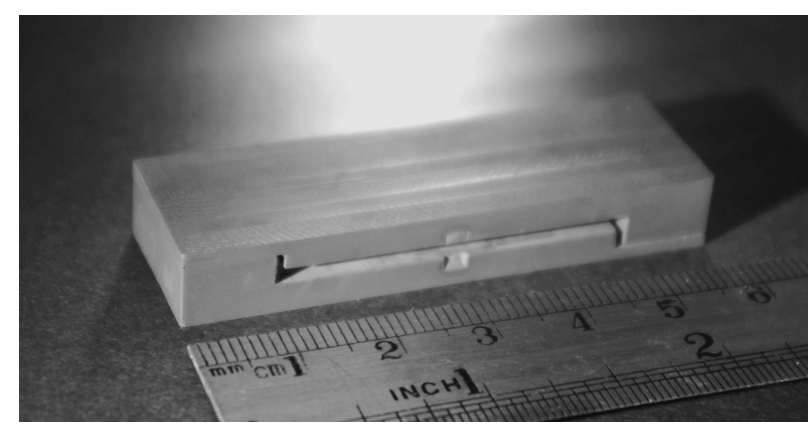

Fig. 3 Appearance of the specially shaped magnet having an original magnetic orientation.

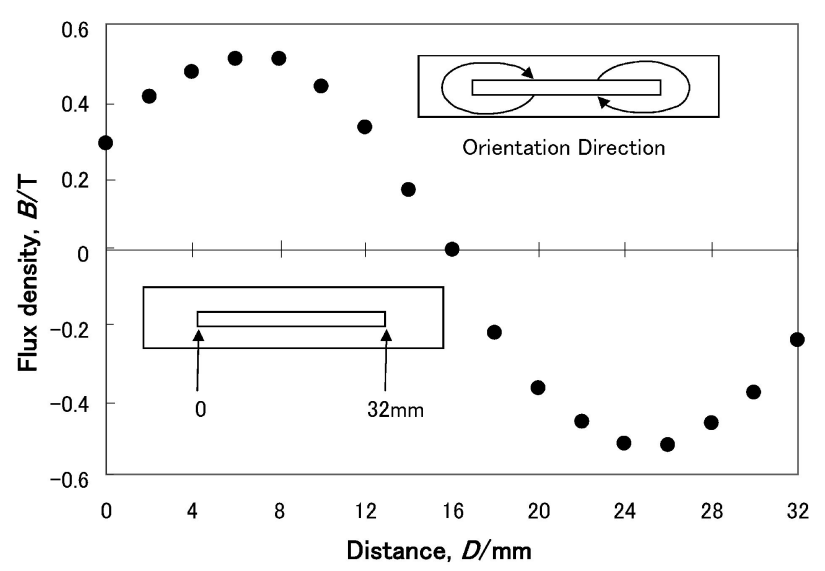

Fig. 4 Flux density distribution in the specially shaped magnet with the maximum fulx density exceeding 0.5 tesla.

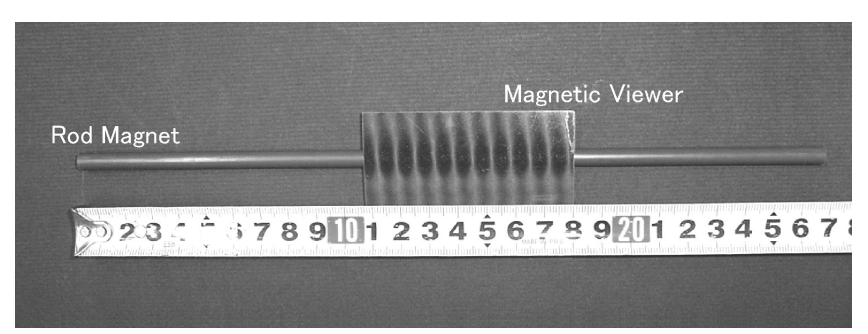

Fig. 5 Appearance of the rod magnet with maximum flux density 0.4 tesla. 


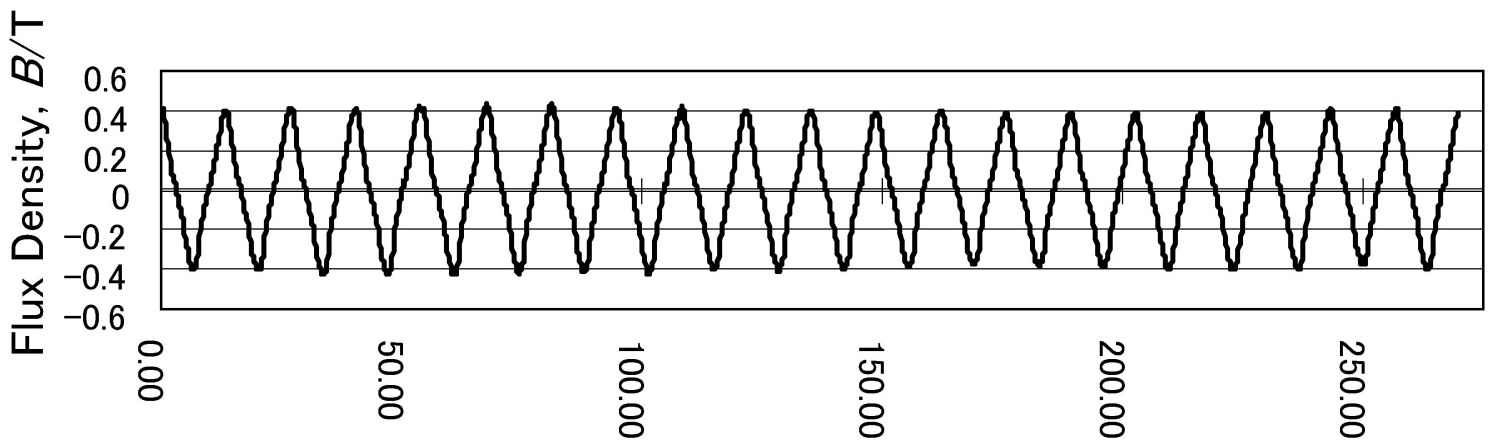

Distance, $D / \mathrm{mm}$

Fig. 6 Flux density distribution of the rod magnet.

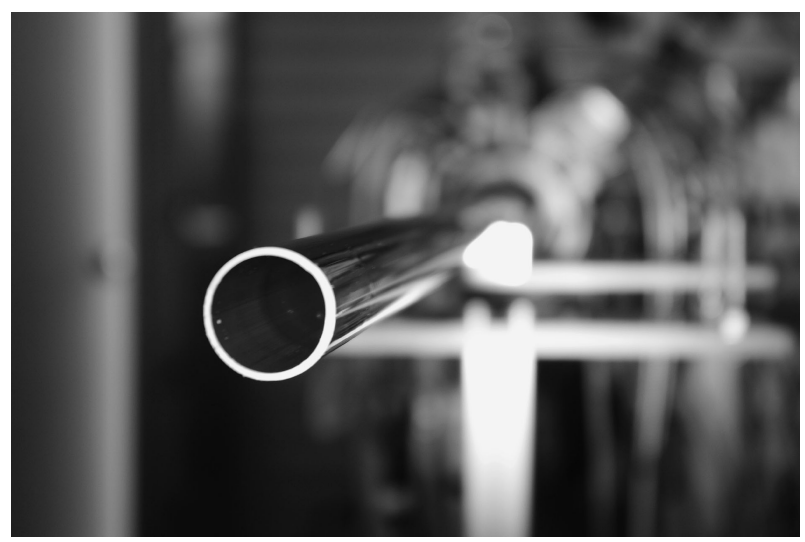

Fig. 7 Photograph of the extrusion test of pipe-shaped magnet.

る. 技術的には押し出し速度や磁石粉末の配向率の観点で, まだまだ改良すべき点は多い，しかし，連続的に磁石を製造 する方法は工業的に意義深い，従って，この異形押出磁石の 研究を続けていきたい.

Fig. 7 は外径 $25 \mathrm{~mm}$, 肉厚 $1 \mathrm{~mm}$ の円筒状成形体を押し 出している様子である。ここでは熱可塑性樹脂を使用してい る.配向方向は概ね極配向であり，極数は 12 である。ただ し, 表面磁束密度は着磁後でも $0.1 \mathrm{~T}$ 程度にとどをる。成形 品の強度を示す圧環強度は $90 \mathrm{MPa}$ である。

\section{7.おわりに}

$\mathrm{SmFeN}$ 発見から 20 年余りが経過した。焼結ができない という久点を克服するために，様々な方法で害用化研究がな されてきた.しかし，この欠点は現時点でも克服されていな い. 従って $\mathrm{NdFeB}$ 磁石の持つ巨大な市場と, その将来の成 長性に比べて, $\mathrm{SmFeN}$ 磁石の勢いが劣ることは明白である.

一方，我々は $\mathrm{SmFeN}$ 磁石の持つ実力を愚直に磨き，プラ スチック磁石の分野で特徵ある使い方を二つ提案している. 一つの提案は粒子の形状をコントロールして保磁力を高め, 結果的に耐熱性を高めること.もう一つの提案は配向プロセ スを極めて, 従来になかった形状や磁気パターンの成形品を 生み出すことである.
ところで，昨今は資源の有効利用という観点が重視され る.とりわけ希土類資源は, 典型的なバランス産業である. この意味で $\mathrm{SmFeN}$ 磁石が再評価される時期が来ていると思 う. 焼結についても, 新プロセス, あるいは従来プロセスの 組反合わせによって進歩する可能性はある。 また, 窒素の果 たす役割について，理論的な解明がさらに進むことが期待さ れる. 最後に, これまでにも増して多くの研究者が, $\mathrm{SmFeN}$ 磁石に携わることを希望する.

文

献

1) J. M. D. Coey and H. Sun: J. Magn. Magn. Mater. 87 (1990) 251.

2) J. M. D. Coey, D. H. Ryan and Y. Boliang: J. Appl. Phys. 55 (1984) 1800.

3) T. K. Kim and M. Takahashi: Appl. Phys. Lett. 20(1972) 492.

4) K. Kobayashi, T. Iriyama, N. Imaoka and T. Fukuda: Rare Eaeths 19(1991) 31.

5) T. Iriyama, K. Kobayashi, N. Imaoka, T. Fukuda, H. Kato and Y. Nakagawa: IEEE Trans. Magn. 28(1992) 2326.

6) N. Imaoka and T. Suzuki: IEEJ Trans. FM. 113(1993) 276.

7) J. M. D. Coey, J. F. Lawier, H. Sun and J. E. M. Allan: J. Appl. Phys. 69(1991) 3007

8) K. Schnitzke, L. Schultz, J. Wecker and M.Katter: Appl. Phys. Lett. $\mathbf{5 7}$ (1990) 2853.

9) J. Ding, Y. Kiu, R. Street and P. G. McCormick: J. Appl. Phys. 75(1994) 1032.

10) M. Katter, J. Wecker and L. Schultz: J. Appl. Phys. 70(1991) 3188.

11) H. Yamamoto, T. Kojima, T. Kumahara and K. Tomii: Papers of Technical Meeting on Magnetics IEEJ MAG-93-245(1993) 11.

12) T.Yoneyama, T.Yamamoto and T. Hidaka: Appl. Phys. Lett. 67 (1995) 3197.

13) F. Kawashima, S. Sakurada, T. Sawa, T. Arai, A. Tsutai and M. Sahashi: IEEE Trans. Magn. 35(1999) 3289.

14) R. Omatsuzawa and T. Iriyama: Denki-Seiko (ELECTRIC FURNACE STEEL) $\mathbf{7 6}(2005) 209$.

15) R. Rani, H. Hegda, A. Navarathna and F. J. Cadieu: J. Appl. Phys. 73(1993) 6023.

16) P. W. Jang, D. Wang and W. D. Doyle: J. Appl. Phys. 81 (1997) 4664.

17) J. M. Song, M. Nakano, N. Ogawa and H. Fukunaga: J. Appl. Phys. 87 (2000) 6585.

18) Y. Otani, A. Moukarika, H. Sun and J. M. D. Coey: J. Appl. Phys. 62(1993) 2874.

19) K. Machida, Y. Nakatani, G. Adachi and A. Onodera: Appl. Phys. Lett. 57 (1990) 2853.

20) H. Izumi, K. Machida, A. Shiomi, M. Iguchi and G. Adachi: Jpn. J. Appl. Phys. 35 (1996) 894.

21) K. Noguchi, K. Machida, K. Yamamoto, M. Nishimura and G. Adachi: Appl. Phys. Lett. 75(1999) 1601. 
22) K. Makita and S. Hirosawa: J. Alloys. Compd. 260(1997) 236.

23) S. Sugimoto, T. Maeda, R. Kobayashi, J. Akedo, M. Lebedev and K. Inomata: IEEE Trans. Magn. 39(2003) 2986.

24) S. Sugimoto, T. Maki, T. Kagotani, J. Akedo and K. Inomata: J. Magn. Magn. Mater. 290-291(2005) 1202.

25) T. Saito: J. Mater. Res. 20(2007) 3130.

26) T. Mashimo, S. Tashiro, S. Hirosawa and K. Makita: J. Appl. Phys. 80(1996) 357.

27) K. Ohmori and K. Shinoyama: J. Appl. Phys. 69 (1991) 5504.

28 A. Kawamoto, T. Ishikawa, S. Yasuda, K. Takeya, K. Ishizaka, T. Iseki and K. Ohmori: IEEE Trans. Magn. 35(1999) 3322.

29) S. Yoshizawa, T. Ishikawa, I. Kaneko, S. Hayashi, A Kawamoto and K. Ohmori: IEEE Trans. Magn. 35(1999) 3340.

30) T. Ishikawa, A. Kawamoto and K. Ohmori: J. Magn. Soc. Jpn. 24(2000) 1394
31) J. O'Sullivan, X. L. Rao and J. M. D. Coey: J. Appl. Phys. 81 (1997) 5124

32) A. Kitazawa and Y. Sakagami: J. Jpn. Soc. Powder Powder Metal. 44(1997) 839.

33) F. Yamashita: J. Magn. Soc. Jpn. 29(2005) 185.

34) F. Yamashita, K. Kawamura, Y. Okada, H. Murakami, M. Ogushi, M. Nakano and H. Fukunaga: J. Appl. Phys. 101 (2007) $09 \mathrm{~K} 522$.

35) H. Fukunaga, H. Murata, T. Yanai, M. Nakano and F. Yamashita: J. Appl. Phys. 107(2010) 09A736.

36) M. Kume, M. Hayashi, M. Yamamoto, K. Kawamura and K. Ihara: IEEE Trans. Magn. 41(2005) 3895.

37) S. Tada, M. Shima, K. Ihara, T. Tomimoto, M. Yamamoto and M. Kume: Digests of the 34th Annual Conference on Magnetics in Japan, (2010) p. 136. 